\title{
Decolourization and cod reduction of textile wastewater by ozonation in combination with biological treatment
}

\section{Z.A. Abidin*, Fahmi, S.A. Ong, S.N.N. Mohd Makhtar, N.R. Rahmat and R. Ahmad}

School of Environmental Engineering, Universiti Malaysia Perlis (UniMAP), 02600 Arau, Perlis, Malaysia

*Email: zulzikrami@unimap.edu.my

Phone: +6049798626; Fax: +6049798636

\begin{abstract}
In this study, the characteristics of colour and chemical oxygen demand (COD) removal of azo dye by ozonation and biological treatment were evaluated for applying in industrial azo dye effluent treatment. Reactive Red 120 has been selected from among azo dyes due to its high solubility in an aquatic environment. The experimentation was arranged in two stages: during the first, only ozonation was performed, while, during the second stage, ozonation was integrated with biological treatment of completely mixed activated sludge (CMAS). COD removal was contributed simultaneously by the ozonation and biological treatment mechanism at lower ozone doses. However, it was significantly the result of direct oxidation at higher ozone doses. Ozonation of dyes usually leads to small organic molecular fragments that lead to a residual COD. The biological treatment is more efficient at mineralizing the by-products of the ozonation, but less efficient at colour reduction than the ozonation process itself. Thus, COD resulting from these small newly formed molecules can be further degraded by biological treatment. Therefore, ozonation should be applied at a medium ozone dose as a pre-treatment for a combined ozonationbiological treatment for azo dye removal.
\end{abstract}

Keywords: Ozonation; azo dye; colour; COD; biological treatment.

\section{INTRODUCTION}

The presence of colour and its causative compounds has always been undesirable in water used for either industrial or domestic needs. Different colouring agents like dyes, inorganic pigments, tannins and lignins usually impart colour. Amongst the many complex types of industrial wastewater with various types of colouring agents, dye wastes are predominant [1]. This wastewater is not only toxic to the biological world, but also contains colour, which blocks sunlight. For these reasons, it causes many problems for the ecosystem [2]. The number of dyes presently used in the textile industry is about 10,000. Among these dyes, azo dyes constitute the largest and the most important class of commercial dyes. Azo dyes are widely used in the textile, plastic, leather, and paper industries as additives [3-5]. The removal of azo dyes from the aquatic environment is important because many azo dyes are toxic to aquatic organisms [6]. Several methods are used for the treatment of dye-containing wastewater. Coagulation is effective for the treatment of insoluble dyestuff wastewater but not so effective for soluble dyestuff wastewater [7]. The adsorption method has difficulties in the treatment of insoluble dyestuff wastewater and it is very difficult to find the desorption process $[8,9]$. The 
chemical method is used to oxidize organic materials using oxidizing agents such as ozone, $\mathrm{H}_{2} \mathrm{O}_{2}$, UV light or combinations of such oxidants, which are known as Advanced Oxidation Processes (AOPs). Most factories use this method to reduce COD and colour. But, it cannot satisfy the environmental discharge standard by itself alone and the cost is relatively high. The combination of ozonation and biodegradation seems to be a promising unit process to remove the residual colour, COD and BOD of wastewater containing dye. The reaction of the oxidizing agent with dye in an aqueous environment leads to a decrease in the aromaticity and molecular weight, which eventually results in an increase in the biodegradability and colour removal of dye. The biodegradable compound produced during ozonation is then removed by the subsequent biodegradation. Therefore, the improvement of biodegradability is considered to be the essential factor that determines the performance of the ozonation-biological treatment process.

Combined treatment processes have been proposed to treat dye-containing wastewater, including $\mathrm{UV} / \mathrm{H}_{2} \mathrm{O}_{2}$ or $\mathrm{UV} / \mathrm{O}_{3}$, followed by biological treatment. Several other researchers have also investigated the application of partial ozonation or AOPs as pre-treatment steps, followed by subsequent biological treatments for treating the dyecontaining [10]treatment for combined chemical-biological treatment is a potential process for enhanced colour removal and biodegradability of wastewaters containing the azo dye Remazol Black B, once the appropriate ozonation period is determined. Fongsatitkul, Elefsiniotis [11] reported that chemical oxidation prior to biodegradation delivered the best performance for treating the dye-containing wastewater, rather than only biological and biological prior to chemical oxidation treatments [12]. Previous studies reported that ozonation effectively decolourized azo dye Reactive Red 120, even at a lower ozone dose [13-15]. However, significant COD removal was only observed within the higher range of ozone doses. Moreover, ozonation transforms the functional groups in azo dye to produce more biodegradable by-products, which are easily removed by biological treatment. In this study, colour and COD removal of Reactive Red 120 (disazo dye) were evaluated for application in the treatment of wastewater containing azo dye. The experimentation was arranged in two main periods: during the first, only ozonation treatment was performed, while during the second period ozonation was integrated with biological treatment. The first period was aimed to evaluate the oxidation process to achieve complete colour removal of dye and partial cleavage of aromatic amines to make them easily biodegradable. Further degradation can be achieved in the second period by treating the effluent from ozonation by the biological treatment.

\section{MATERIALS AND METHODS}

\section{Materials}

The Reactive Red 120 (RR120, $\mathrm{C}_{44} \mathrm{H}_{30} \mathrm{Cl}_{2} \mathrm{~N}_{14} \mathrm{O}_{20} \mathrm{~S}_{6}$, and M.W. = 1,469.98 g/mol) were of analytical grade (Sigma-Aldrich) and used without further purification. The chemical structure of the dyes is shown in Figure 1. A stock solution of $10,000 \mathrm{mg} / \mathrm{L}$ was used for the preparation of $100 \mathrm{mg} / \mathrm{L}$ dye concentrations by dilution. The $\mathrm{pH}$ of aqueous solutions was adjusted using $0.1 \mathrm{~N} \mathrm{NaOH}$ to raise the $\mathrm{pH}$ or $0.1 \mathrm{~N} \mathrm{HCl}$ to lower the $\mathrm{pH}$ upon decolourization and degradation. All solutions were prepared using ultrapure water.

\section{Stage 1: Pre-ozonation Treatment}

The experimental setup consists of an oxygen cylinder, ozone generator, glass reactor and KI reactor. Ozone was generated from the A2ZZ-3G ozone generator utilizing pure oxygen of $99.5 \%$ concentration, introduced at a rate of $3 \mathrm{~L} / \mathrm{min}$. Ozone applications were 
semi-batch reactions carried out in a cylindrical glass reactor $(450 \times 85 \mathrm{~mm}$ ID) of a 2,000 $\mathrm{mL}$ working volume. The dye solution with a concentration of $100 \mathrm{mg} / \mathrm{L}$ was added into the glass reactor. Constant ozone was supplied from the bottom of the reactor through a diffuser at a dosage of $10.2 \mathrm{mg} / \mathrm{min}$. The treatment was evaluated at $0,1,2,3,4,5,10$,

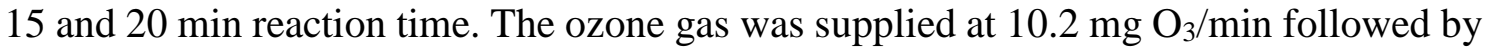
aeration for $5 \mathrm{~min}$ to remove residual ozone. All connections from the ozone generator to the reactor were made through Teflon tubing. The excess ozone leaving the reactor was decomposed through $2,000 \mathrm{~mL}$ conical flasks filled with $2,000 \mathrm{~mL}$ of $2 \% \mathrm{KI}$ solution. The experiments were conducted at room temperature, and samples were withdrawn at definite time intervals for determination of $\mathrm{pH}$, colour, COD and $\mathrm{UV}$-vis spectra analysis.<smiles>O=S(=O)(O)c1cc(Nc2nc(Cl)nc(Nc3ccc(Nc4nc(Cl)nc(Nc5cc(S(=O)(=O)O)cc6cc(S(=O)(=O)O)c(N=Nc7ccccc7S(=O)(=O)O)c(O)c56)n4)cc3)n2)c2c(O)c(N=Nc3ccccc3S(=O)(=O)O)c(S(=O)(=O)O)cc2c1</smiles>

Figure 1. Chemical structure of RR120.

\section{Stage 2: Biological Treatment}

The biological treatment was performed by an aerobic CMAS reactor consisting of a 0.15 $\mathrm{m}$ deep cylindrical glass with an internal diameter of $0.10 \mathrm{~m}$. The aerobic activated sludge as seed was collected from the biological treatment system of a glove manufacturing plant, located in Perlis, Malaysia. The bioreactor had an operating liquid volume of 1,000 $\mathrm{mL}$ and was equipped with an air diffuser and stirrer. The air was bubbled at the bottom of the reactor by an air diffuser. Agitation was maintained during the whole experiment in order to mix the medium and avoid concentration gradients within the bioreactor. The DO concentration in the medium was monitored daily to ensure oxygen concentrations between $6-8 \mathrm{mg} / \mathrm{L}$. The overall experiments were conducted at room temperature.

The CMAS reactor operated in batch mode, with $24 \mathrm{~h}$ treatment cycles consisting of four consecutive phases: filling, reaction, settling and drawing. The bioreactor was previously seeded by $500 \mathrm{~mL}$ of aerobic activated sludge. Then, at the beginning of the filling cycle, the reactor was filled with $500 \mathrm{~mL}$ of pretreated dye influent. Subsequently, aeration and agitation were switched on to begin the reaction phase to allow the biological removal of biodegradable pollutants. Once completed, both aeration and agitation were stopped to let the biomass settle down. Finally, after $1 \mathrm{~h}$ of settling phase, approximately $300 \mathrm{~mL}$ volume of samples was withdrawn from the supernatant during the drawing phase, without disturbing the settled sludge. The bioreactor was replaced with an equal volume of pretreated dye samples, and aeration-agitation was turned on again for new treatment cycles. The dye samples were subject to pre-ozonation with $0,5,10,15$ and 20 min contact times. Furthermore, they were left for approximately $24 \mathrm{~h}$ before feeding into the bioreactor. Therefore, possible interference from any quantity of residual DO in the biological treatment was eliminated. Samples from each reactor were collected daily 
(until day 30) and then filtered through a $0.45 \mu \mathrm{m}$ glass microfibre filter (Fisherbrand, 25 $\mathrm{mm})$ prior to analysis to remove the biomass.

\section{Analytical Methods}

The ozone concentration in the feed gas was determined by the KI-starch titration method [16]. The decolourization and degradation of azo dye were determined by measurements of absorbance at wavelengths ranging from 200 to $800 \mathrm{~nm}$ by a UV-vis spectrophotometer (Hitachi U-2810). The maximum visible region $\left(\lambda_{\max } 535 \mathrm{~nm}\right)$ was employed as a base for characterization of decolourization for RR120, using a $10 \mathrm{~mm}$ quartz cell. The $\mathrm{pH}$ was measured by a Hanna Instruments HI223 pH meter. COD was determined in accordance with the closed reflux, colorimetric method [16].

\section{RESULTS AND DISCUSSION}

\section{Effect of Pre-ozonation on Colour and COD Removal}

Figure 2 presents the colour removal of RR120 at different contact times. It was observed that complete decolourization occurred only after $10 \mathrm{~min}$ reaction. The removal was due to the fact that ozone is able to cleave the azo bonds from the dyes. The ozone as a powerful oxidant can oxidize the unsaturated bonds and achieve almost complete decolourization with an ozone flow rate of $10.2 \mathrm{mg} \mathrm{O} / \mathrm{min}$. This finding supports previous research that the ozonation of dyes in decolourization was excellent $[2,17,18]$. The $\mathrm{pH}$ decreased during the treatment from 7 to 3 . Therefore, it is apparent that the direct reaction by ozone molecules is predominant under this acidic condition. The decrease was caused by both the formation of acidic degradation by-products such as $\mathrm{H}_{2} \mathrm{SO}_{4}$ originating from the sulphonic groups, and consumption of hydroxyl radicals in the ozonation decomposition [19].

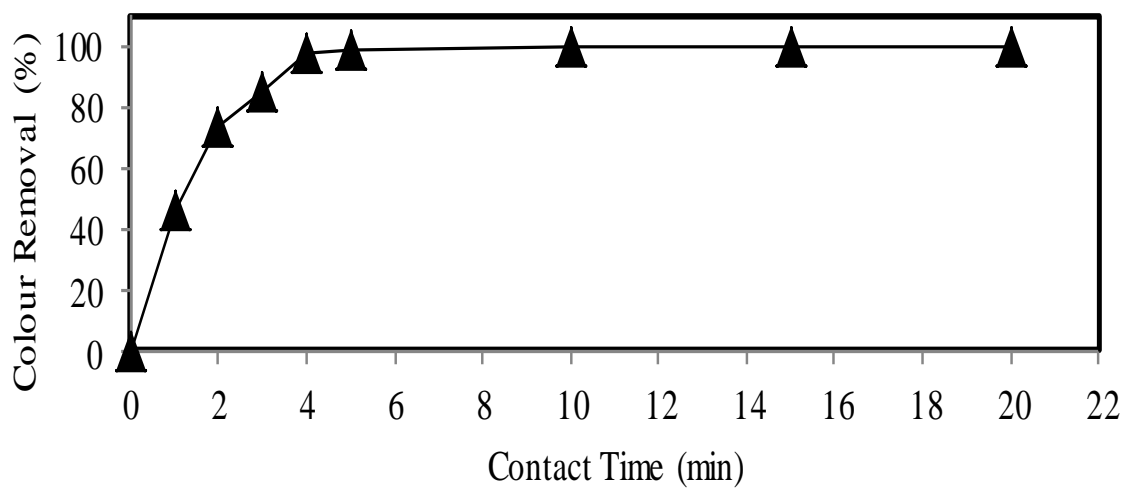

Figure 2. Colour removal for RR120 at different contact times.

The effect of pre-ozonation on the UV-vis spectra of RR120 after 20 min of treatment is shown in Figure 3. The peak slowly collapsed with the increase of contact time, and finally no peak was observed by 20 min of ozonation. The spectra of the initial solution represent the UV band characteristics of $-\mathrm{N}=\mathrm{N}$ - groups $(535 \mathrm{~nm})$ and related it to the benzene and naphthalene rings bonded to the $-\mathrm{N}=\mathrm{N}$ - groups (220 and $322 \mathrm{~nm}$ ) [1921]. Within the near ultraviolet region $(260 \mathrm{~nm})$, the absorption band results from the unsaturated character of benzene and naphthalene rings. During the experiment, the intensity of absorption at $535 \mathrm{~nm}$ declined extremely rapidly; however, the UV band at 
220 and $322 \mathrm{~nm}$ disappeared more slowly than the visible band. This resulted in the decolourization of the dye sample. The colour removal percentage reached $100 \%$ by 10 min of contact time.

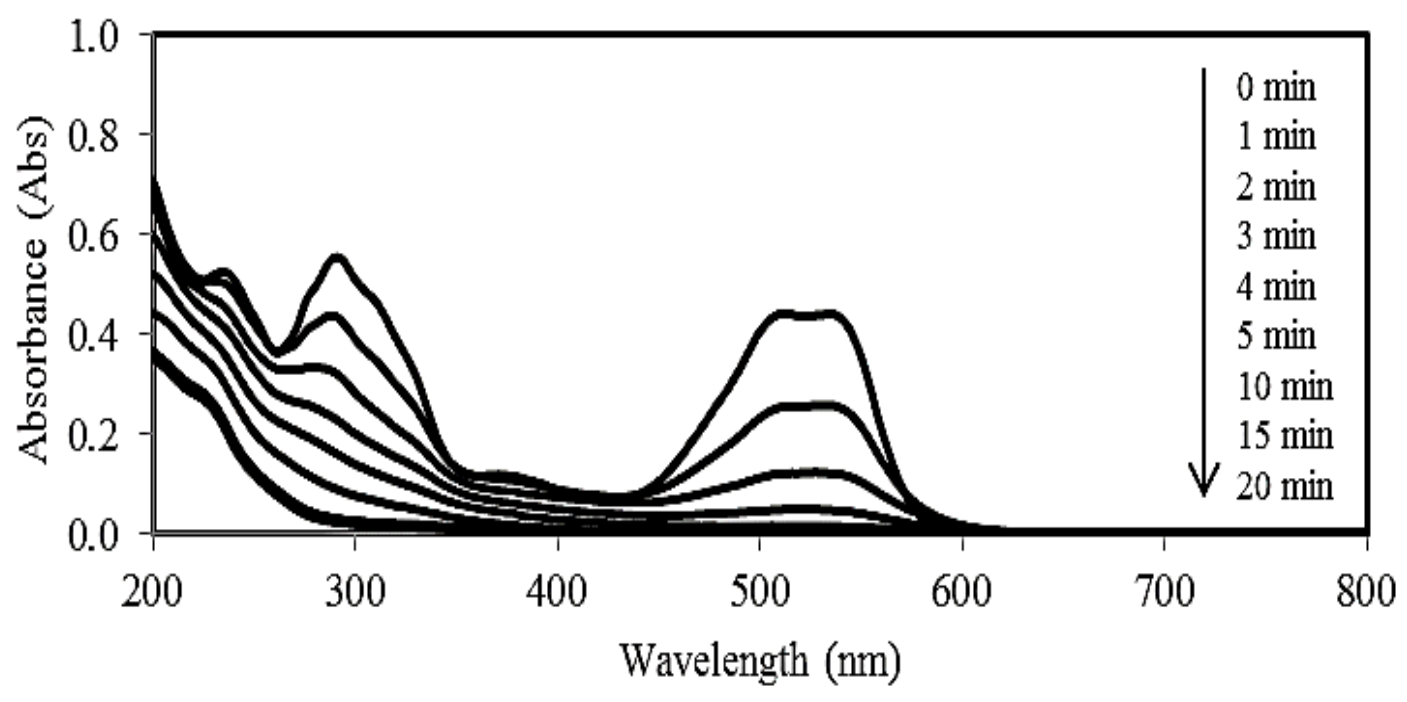

Figure 3. UV-vis absorbance spectra in relation to ozonation time of RR120.

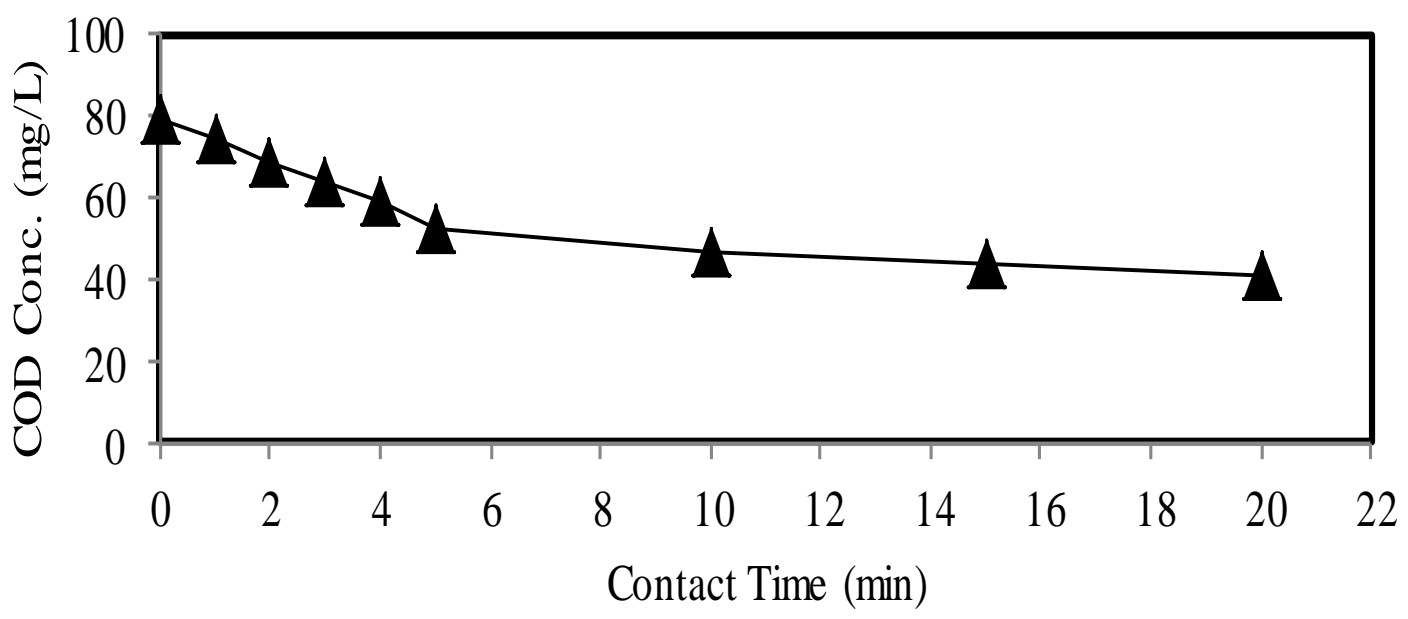

Figure 4. COD removal in relation to ozonation time of RR120.

Figure 4 shows the COD value for RR120 after ozonation. The contact times carried out are 1, 2, 3, 4, 5, 10, 15 and 20 min. For a given time, an increase in contact time resulted in an increase in the COD removal efficiency. The initial COD value is 86 $\mathrm{mg} / \mathrm{L}$, and decreases to $42 \mathrm{mg} / \mathrm{L}$. However, at 15 and $20 \mathrm{~min}$, there are no significant changes in the COD value. The removal percentage at the initial dye concentration of 100 $\mathrm{mg} / \mathrm{L}$ was $50 \%$ after $20 \mathrm{~min}$. The removal percentage increased with the increase of contact time, which indicated that the dye structure was destroyed during ozonation and partially mineralized to small organic molecules. 


\section{Effect of Pre-ozonation on CMAS Treatment for Colour and COD Removal}

Figure 5 shows the wavelength of RR120 indicated by the UV-vis spectrophotometer, subjected to different pre-ozonation contact times and CMAS biological treatments (day 0 and 30). The specified wavelength peaks of 5,10, 15 and 20 min ozonation have disappeared, which indicates that the chemical structure of the synthetic dyes was transformed by ozonation [22]. The dramatic changes of UV spectra represent the disappearance of both azo and aromatic groups in the course of RR120. For longer ozonation times, there is a greater reduction through biological treatment. However, the biological treatment seems to have no influence on the colour removal of RR120 without pre-ozonation $(0 \mathrm{~min})$. Therefore, the biological treatment alone is not sufficient for decolourization of dye-containing wastewaters. Nevertheless, it seemed possible to obtain bio-treatable solutions once the colour had disappeared. The biological process is more efficient at mineralizing the by-products of the ozonation, but less efficient at colour reduction than the ozonation process itself $[17,23]$.

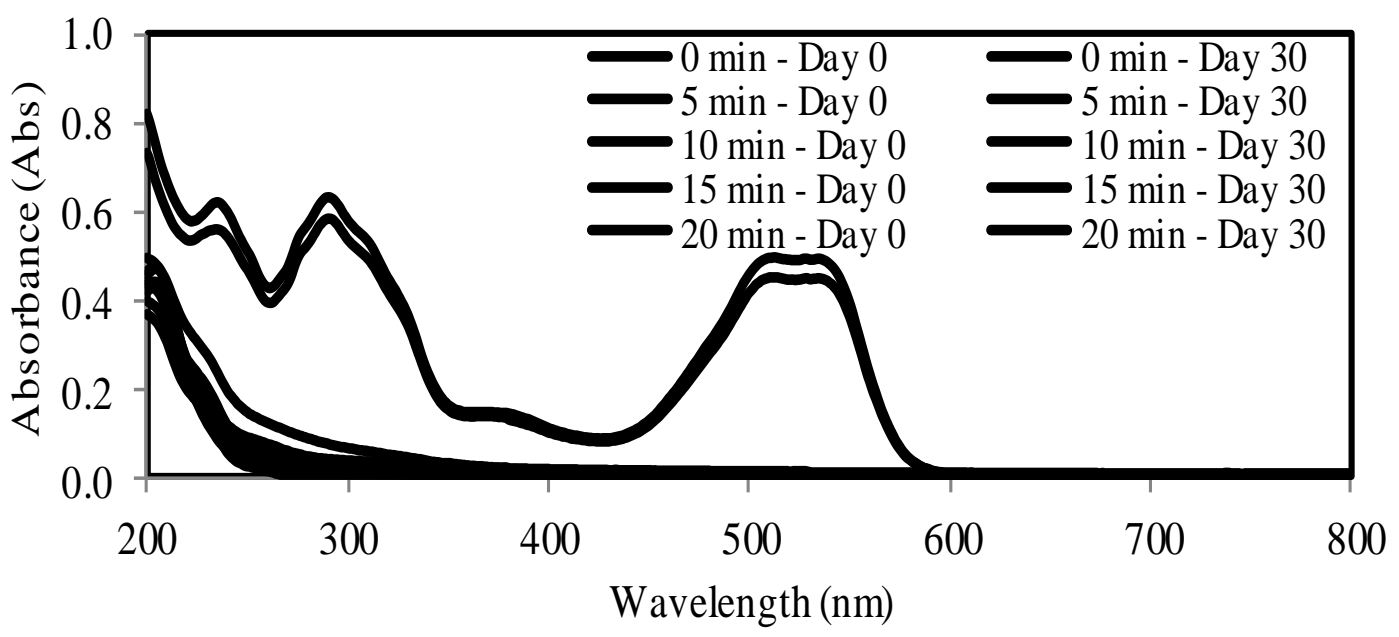

Figure 5. UV-vis absorbance spectra of RR120 pre-ozonation and biological treatment.

Figure 6 shows the COD concentration in relation to ozonation time of RR120 CMAS biological treatment. The concentrations gradually decrease from the initial concentrations of 58, 50, 46 and $44 \mathrm{mg} / \mathrm{L}$ for 5, 10, 15 and 20 min ozonation, respectively. However, after day 30 of biological treatment, mere pre-ozonation of 10, 15 and 20 min shows a significant trend of reduction. These results imply that subsequent biological treatment after ozonation for 10 min was effective enough for the reduction of the COD concentration. The results from pre-ozonation alone contributed more than $50 \%$ of the total COD removal, which indicated that at the highest ozone dose $(20 \mathrm{~min})$, ozonation tends to mineralize the azo dye [24]. On the other hand, at medium ozone doses (5 to 10 $\mathrm{min}$ ), the role of ozonation seems to break down the dye molecule and create an ozonation product that is easily biodegraded in the biological treatment. Therefore, ozone was not oxidized azo dye though complete mineralization to produce $\mathrm{CO}_{2}$ and $\mathrm{H}_{2} \mathrm{O}$. Khadhraoui, Trabelsi [19] mentioned that ozonation of dyes usually leads to small organic molecular fragments, such as acetic acids, epoxides, aldehydes, and ketones that lead to a residual COD. Therefore, the COD resulting from these small newly formed molecules can be 
further degraded by a biological process. Thus, it is recommended that ozonation should be applied at a medium ozone dose as a pre-treatment for combined chemical-biological treatment for azo dye removal.

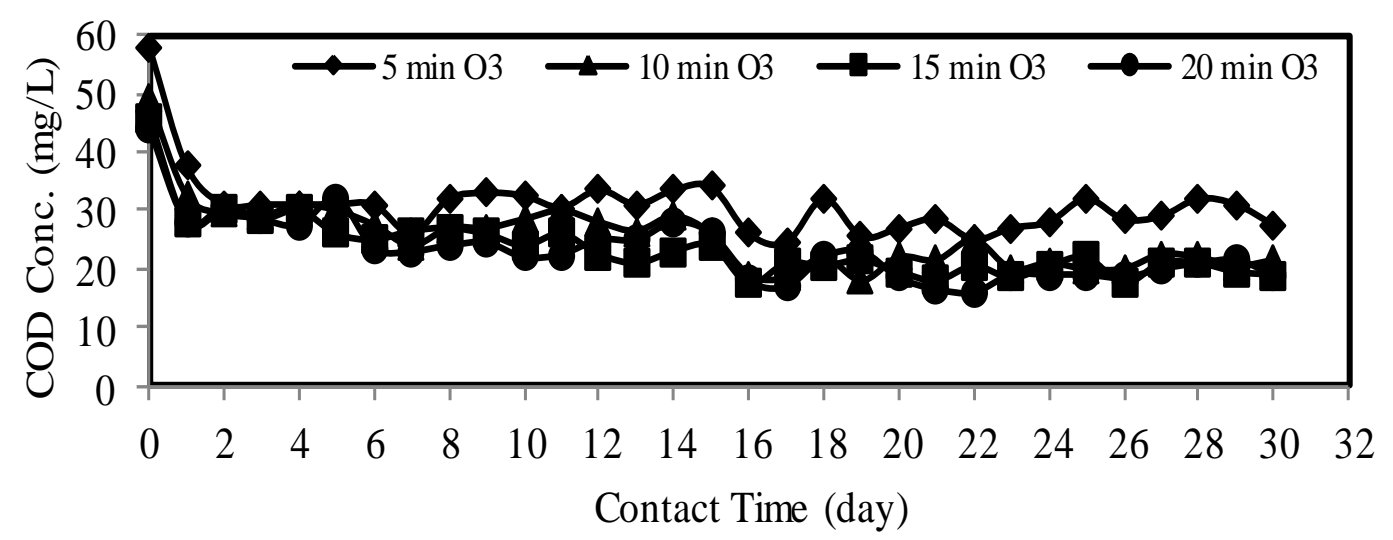

Figure 6. COD concentration in relation to pre-ozonation time and biological treatment of RR120, $100 \mathrm{mg} / \mathrm{L}$ and $\mathrm{pH}$.

\section{CONCLUSIONS}

In this study, the characteristics of colour and COD removal of RR120 azo dye by preozonation followed by CMAS treatment were evaluated for application in industrial azo dye effluent treatment. The drop of $\mathrm{pH}$ indicated the formation of acidic by-products. Based on the results, the biological treatment is more efficient at mineralizing the byproducts of the ozonation, but less efficient at colour reduction than the ozonation process itself. Furthermore, the COD removal was contributed simultaneously by ozonation and the biological treatment mechanism at lower ozone doses. However, it was significantly contributed by direct oxidation at the highest ozone dose. Ozonation of dyes usually leads to small organic molecular fragments that lead to a residual COD. Therefore, the COD resulting from these small newly formed molecules can be further degraded by biological treatment. Thus, it is recommended that ozonation should be applied at medium ozone doses as a pre-treatment for combined ozonation-biological treatment for azo dye removal.

\section{ACKNOWLEDGEMENTS}

The authors thank the Ministry of Higher Education (MOHE), Malaysia for the financial support (FRGS 9003-00282), and the School of Environmental Engineering, Universiti Malaysia Perlis (UniMAP) for providing all the equipments and facilities.

\section{REFERENCES}

[1] Anjaneyulu Y, Chary NS, Raj DSS. Decolourization of industrial effluentsavailable methods and emerging technologies-a review. Reviews in Environmental Science and Bio/Technology. 2005;4:245-73. 
[2] Choi JW, Song HK, Lee W, Koo K-K, Han C, Na B-K. Reduction of COD and color of acid and reactive dyestuff wastewater using ozone. Korean Journal of Chemical Engineering. 2004;21:398-403.

[3] Chung Y-C, Chen C-Y. Degradation of azo dye reactive violet 5 by $\mathrm{TiO}_{2}$ photocatalysis. Environmental Chemistry Letters. 2009;7:347-52.

[4] Amenaghawon NA, Osarumwense JO, Aisien FA, Olaniyan OK. Preparation and investigation of the photocatalytic properties of periwinkle shell ash for tartrazine decolourisation. Journal of Mechanical Engineering and Sciences. 2014; 7:107084.

[5] Amenaghawon NA, Osarumwense JO, Aisien FA, Olaniyan OK. Photocatalytic decolorization of tartrazine using periwinkle shell ash: effect of operational variables, kinetic and isotherm study. International Journal of Automotive and Mechanical Engineering. 2015;11:2555-70.

[6] Sharma S, Sharma S, Pathak S, Sharma K. Toxicity of the azo dye methyl red to the organisms in microcosms, with special reference to the guppy (Poecilia reticulata Peters). Bulletin of environmental contamination and toxicology. 2003;70:0753-60.

[7] Kuo W. Decolorizing dye wastewater with Fenton's reagent. Water Research. 1992;26:881-6.

[8] Ledakowicz S, Solecka M, Zylla R. Biodegradation, decolourisation and detoxification of textile wastewater enhanced by advanced oxidation processes. Journal of Biotechnology. 2001;89:175-84.

[9] Kim SH, Kim TW, Cho DL, Lee DH, Kim JC, Moon H. Application of characterization procedure in water and wastewater treatment by adsorption. Korean Journal of Chemical Engineering. 2002;19:895-902.

[10] Lu X, Yang B, Chen J, Sun R. Treatment of wastewater containing azo dye reactive brilliant red $\mathrm{X}-3 \mathrm{~B}$ using sequential ozonation and upflow biological aerated filter process. Journal of Hazardous Materials. 2009;161:241-5.

[11] Fongsatitkul P, Elefsiniotis P, Yamasmit A, Yamasmit N. Use of sequencing batch reactors and Fenton's reagent to treat a wastewater from a textile industry. Biochemical Engineering Journal. 2004;21:213-20.

[12] Sakinah M, Amirruddin A, Kadirgama K, Ramasamy D, Rahman M, Noor M. The application of response surface methodology in the investigation of the tribological behavior of palm cooking oil blended in engine oil. Advances in Tribology. 2016;2016.

[13] Nazerry Rosmady R, Fahmi Muhammad R, Che Zulzikrami AA, Apipah A. Multi-stage ozonation and biological treatment for the removal of azo dye industrial effluent. 2010.

[14] Fahmi MR, Abidin CZA, Rahmat NR. Characteristic of colour and COD removal of azo dye by advanced oxidation process and biological treatment. International Conference on Biotechnology and Environment Management IPCBEE2011. p. 13-8.

[15] Che Zulzikrami Azner A, Muhammad Ridwan F, Ong S-A, Siti Nurfatin Nadhirah MM, Nazzery Rosmady R. Decolourization of an azo dye in aqueous solution by ozonation in a semi-batch bubble column reactor. 2015.

[16] Federation WE, Association APH. Standard methods for the examination of water and wastewater. American Public Health Association (APHA): Washington, DC, USA. 2005. 
[17] Qi L, Wang X, Xu Q. Coupling of biological methods with membrane filtration using ozone as pre-treatment for water reuse. Desalination. 2011;270:264-8.

[18] Gomes AC, Fernandes LR, Simões RM. Oxidation rates of two textile dyes by ozone: effect of $\mathrm{pH}$ and competitive kinetics. Chemical Engineering Journal. 2012;189:175-81.

[19] Khadhraoui M, Trabelsi H, Ksibi M, Bouguerra S, Elleuch B. Discoloration and detoxicification of a Congo red dye solution by means of ozone treatment for a possible water reuse. Journal of Hazardous Materials. 2009;161:974-81.

[20] Wang A, Qu J, Liu H, Ge J. Degradation of azo dye Acid Red 14 in aqueous solution by electrokinetic and electrooxidation process. Chemosphere. 2004;55:1189-96.

[21] Solozhenko E, Soboleva N, Goncharuk V. Decolourization of azodye solutions by Fenton's oxidation. Water Research. 1995;29:2206-10.

[22] Ulson SMdAG, Bonilla KAS, de Souza AAU. Removal of COD and color from hydrolyzed textile azo dye by combined ozonation and biological treatment. Journal of Hazardous Materials. 2010;179:35-42.

[23] Karthik V, Saravanan K, Bharathi P, Dharanya V, Meiaraj C. An overview of treatments for the removal of textile dyes. Journal of Chemical and Pharmaceutical Sciences. 2014;7:1215-20.

[24] Gökçen F, Özbelge TA. Pre-ozonation of aqueous azo dye (Acid Red-151) followed by activated sludge process. Chemical Engineering Journal. 2006;123:109-15. 